\title{
Activation of HTLV-I Transcription in the Presence of Tax Is Independent of the Acetylation of CREB-2 (ATF-4)
}

\author{
F. Gachon, ${ }^{1}$ C. Devaux, and J.-M. Mesnard ${ }^{2}$ \\ Laboratoire Infections Rétrovirales et Signalisation Cellulaire, CNRS EP 2104/Université Montpellier I, Institut de Biologie, \\ 4 Bd Henri IV, 34060 Montpellier, France
}

Received December 14, 2001; returned to author for revision February 22, 2002; accepted March 22, 2002

\begin{abstract}
We have previously demonstrated that the bZIP transcription factor CREB-2, also called ATF-4, trans-activates, in association with the viral protein Tax, the human T-cell leukemia virus type I (HTLV-I) promoter. In this study, we have examined whether CREB-2 acetylation affects transcriptional activation mediated by Tax. We present evidence that CREB-2 is acetylated in vitro and in vivo. CREB-2 is acetylated in two regions: the basic domain of the bZIP (from amino acid residue 270 to 300 ) and the short basic domain (from 342 to 351) located downstream from the bZIP. We also demonstrate that CREB-2 is acetylated by $\mathrm{p} 300 / \mathrm{CBP}$ but not by p/CAF. Moreover, replacement of lysine by arginine in the basic domains decreases the trans-activating capacity of CREB-2. However, in the presence of Tax, the HTLV-I transcription remains fully activated by these CREB-2 mutants. Although we cannot totally exclude that the mutations could also affect CREB-2 structure and activity independent of acetylation, our results suggest that activation of the viral promoter in the presence of Tax is independent of the CREB-2 acetylation. ๑ 2002 Elsevier Science (USA)
\end{abstract}

\section{INTRODUCTION}

Human T-cell leukemia virus type I (HTLV-I) is the etiologic agent of adult T-cell leukemia (ATL). The viral Tax protein has been proposed to contribute to the proliferation and the transformation of T-cells by HTLV-I (reviewed in Mesnard and Devaux, 1999; Yoshida, 2001). Tax is also a potent transactivator of transcription from the viral long terminal repeat (LTR) promoter (Cann et al., 1985; Felber et al., 1985; Fujisawa et al., 1985; Sodroski et al., 1985). The HTLV-I LTR contains important elements needed for Tax trans-activation corresponding to three repeats of 21-bp sequence called Tax-responsive elements (TxREs) (Fujisawa et al., 1986; Shimotohno et al., 1986). The viral TxREs are composed of a central cyclicAMP response element (CRE)-like motif, flanked by short runs of guanine and cytosine base pairs. However, Tax is unable to interact specifically with the CRE site and, in fact, is associated with the viral LTR through interactions with CRE-binding proteins. Different members of the activating transcription factor/CRE-binding protein (ATF/ CREB) family such as CREB (Zhao and Giam, 1992; Franklin et al., 1993; Yin and Gaynor, 1996), CREM (Suzuki et al., 1993), and CREB-2 (Reddy et al., 1997; Gachon et al., 1998) were shown to be able to stimulate viral

\footnotetext{
${ }^{1}$ Present address: Department of Molecular Biology, Sciences II, University of Geneva, 30 Quai Ernest Ansermet, CH-1211 Geneva-4, Switzerland.

${ }^{2}$ To whom correspondence and reprint requests should be addressed. Fax: (33) 4676044 20. E-mail: mesnard@crbm.cnrs-mop.fr.
}

transcription in the presence of Tax. The ATF/CREB proteins are characterized by basic-leucine zipper (bZIP) C-terminal structures required for DNA binding and protein dimerization. Tax enhances the binding of CREB (Zhao and Giam, 1992; Franklin et al., 1993; Yin and Gaynor, 1996), CREM (Suzuki et al., 1993), and CREB-2 (Gachon et al., 2000) to the TxREs, probably by stabilizing the LTR-bound complexes through direct contacts with nucleotides flanking the CRE-like motifs (Kimzey and Dynan, 1998; Lenzmeier et al., 1998; Lundblad et al., 1998). It has also been suggested that Tax could increase the DNA-binding activity of ATF/CREB factors by promoting dimerization of their bZIP domain (Wagner and Green, 1993). Then, the TxRE-associated Tax molecule is able to recruit histone acetyltransferases (HATs), such as the CREB-binding protein (CBP) and its homolog, p300 (Kwok et al., 1996), or the p300/CBP-associated factor (p/CAF) (Jiang et al., 1999) and basal polymerase II factors such as the transcription factors TFIIA (Clemens et al., 1996) or TFIID through TATA-binding protein (TBP) (Caron et al., 1993) and TBP-associated factor TAF 28 (Caron et al., 1997).

CREB-2 (Karpinski et al., 1992), also called ATF-4 or TAXREB-67 (Hai et al., 1989; Tsujimoto et al., 1991), together with the mouse mATF-4, mTR67, C/ATF, and the Aplysia ApCREB-2, represent a subfamily of the ATF/ CREB proteins (Hai and Hartman, 2001). CREB-2 contains a constitutive activation domain of transcription that can directly interact with p300/CBP (Liang and Hai, 1997; Gachon et al., 2000). CREB-2 is known to form heterodimers with members of activator protein-1 (AP-1) and 


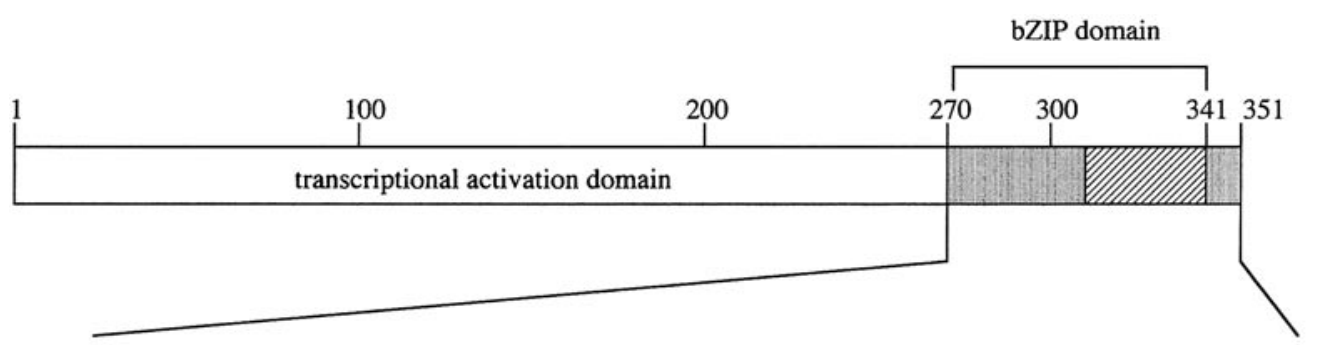

AAKVKGEKLDKKLKKMEQNKTAATRYRQKKRAEQEAL.....L......L......L......L......VRKARGKKRVP

FIG. 1. Schematic diagram of transcription factor CREB-2. The C-terminal part of CREB-2 contains, in addition to the bZIP domain, a short basic region corresponding to the last 10 amino acid residues (from 342 to 351). We have already demonstrated that the leucine zipper and the short basic C-terminal domain of CREB-2 are required for interacting with Tax (Gachon et al., 2000). Both basic domains and the leucine zipper are indicated by the grayish and stripped boxes, respectively. The amino acid sequence of the C-terminal part (from 270 to 351 ) is indicated.

CCAAT/enhancer-binding protein (C/EBP) families rather than proteins of the ATF/CREB family (Hai and Curran, 1991; Vinson et al., 1993; Gachon et al., 2001). Heterodimerization of CREB-2 represents a powerful means to regulate its transcriptional activity and consequently the expression of its target genes. Thus, we recently demonstrated that the heterodimerization of CREB-2 with C/EBP-homologous protein (CHOP) downregulated the HTLV-I transcription (Gachon et al., 2001). Acetylation is also a key mechanism used by the cell to control the activity of a transcription factor. For instance, acetylation of p53 and GATA-1 by p300/CBP (Gu and Roeder, 1997; Boyes et al., 1998) increases their transcriptional activity, while acetylation of T-cell factor (TCF) represses its activity (Waltzer and Bienz, 1998). Because CREB-2 interacts with p300/CBP (Liang and Hai, 1997; Gachon et al., 2000), we explored the possibility that CREB-2 is also regulated by acetylation and we studied the effects of the CREB-2 acetylation on the HTLV-I transcription. Our results demonstrate that CREB-2 is acetylated by p300/ CBP but suggest, however, that in the presence of Tax the activation of HTLV-I transcription is independent of the CREB-2 acetylation.

\section{RESULTS}

\section{CREB-2 is acetylated in vitro and in vivo}

Acetylation has been shown to regulate the activity of many transcription factors. The $\mathrm{C}$-terminal region of CREB-2 including the bZIP domain (Fig. 1) contains lysine residues that are flanked by sequences conform to the consensus for the acetylation of nonhistone proteins (K/RXKK) suggested from studies of p53 and GATA-1 acetylation (Gu and Roeder, 1997; Boyes et al., 1998). To determine whether CREB-2 is acetylated, a GST-CREB-2 fusion protein bound to glutathione-Sepharose beads was incubated with CEM nuclear extract, extensively washed, and subjected to an acetyltransferase assay. As shown in Fig. 2A, GST-CREB-2 was acetylated but not GST alone, showing that the in vitro acetylation was specific to CREB-2. In addition, the same assay was performed with Tax but we detected no acetylation, sug-
A

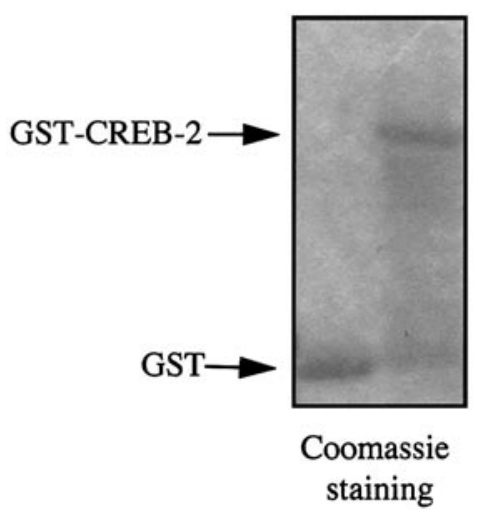

B

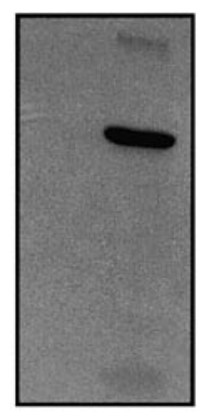

pre-immune anti-CREB-2

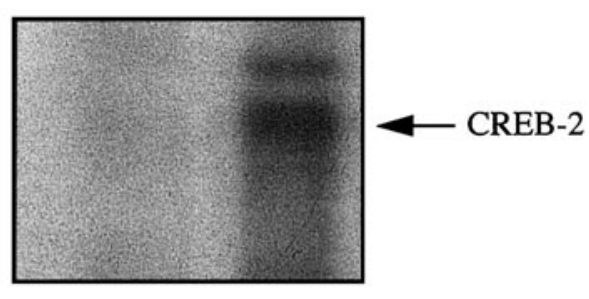

FIG. 2. CREB-2 is acetylated in vitro and in vivo. (A) In vitro acetylation of CREB-2. Equivalent amount of GST and GST-CREB-2 bound to glutathione-Sepharose beads were incubated with CEM nuclear extract, extensively washed, and subjected to an acetyltransferase assay. Reaction products were separated by 10\% SDS-PAGE and the gel was Coomassie blue stained, dried, and visualized by autoradiography. (B) CREB-2 is acetylated in vivo. Extract from CEM cells pulsed with ${ }^{3} \mathrm{H}$-sodium acetate was subjected to immunoprecipitation with preimmune serum or CREB-2 antiserum and immunoprecipitated proteins were analyzed by $10 \%$ SDS-PAGE followed by autoradiography. 
A

CREB-2 WT : $1-351$

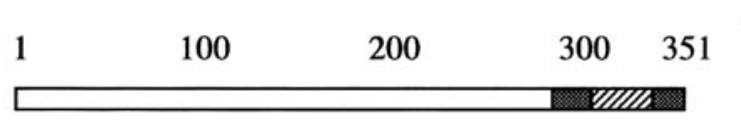

Acetylation

$1-341$

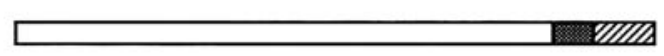

IIII

$1-305$

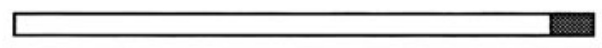

$1-262$

263-351

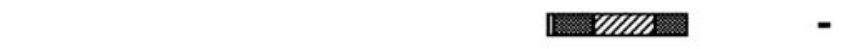

$1-351 \Delta 263-300$
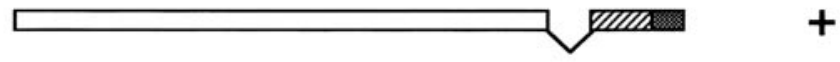

$1-341 \Delta 263-300$
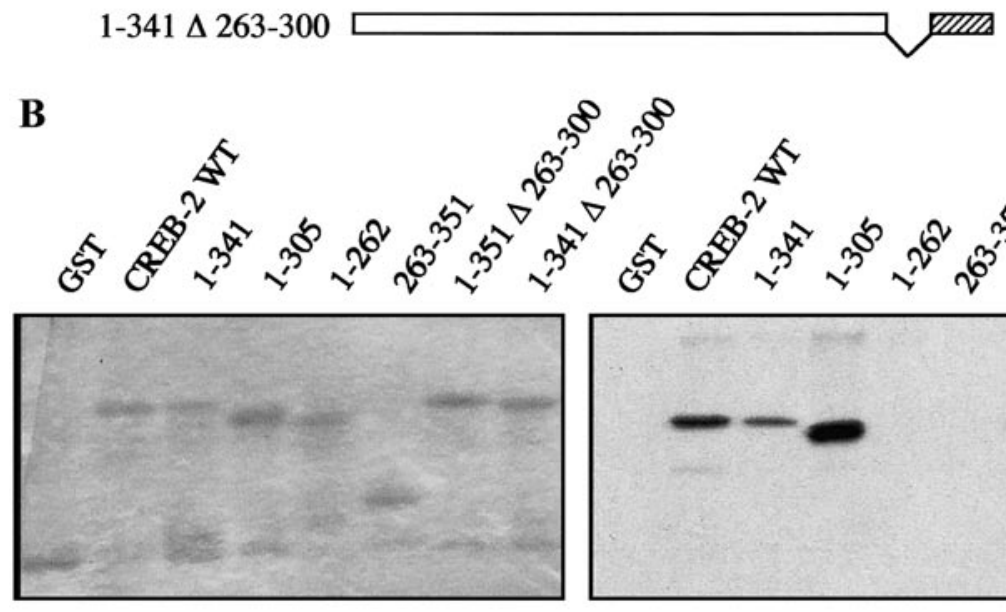

Coomassie staining

Acetylation

FIG. 3. Identification of acetylated domains of CREB-2. (A) Schematic representation of the CREB-2 fragments used for the acetyltransferase assay. (B) Acetylation of CREB-2 occurs at sites located in its C-terminal basic domains. GST-CREB-2 fragments on glutathione-Sepharose beads were incubated with CEM nuclear extract and ${ }^{3} \mathrm{H}$-acetyl-COA. Acetylated proteins were resolved by $10 \%$ SDS-PAGE.

gesting that Tax is probably not acetylated (data not shown).

To verify CREB-2 acetylation in vivo, CEM cells were biosynthetically labeled for $1.5 \mathrm{~h}$ with ${ }^{3} \mathrm{H}$-sodium acetate. The cells were lysed and protein was immunoprecipitated using an anti-CREB-2 serum. Figure 2B shows that cellular CREB-2 was acetylated. No signal was detected in the control immunoprecipitate from the same extract using preimmune serum. These results show that acetylation of CREB-2 occurs in vivo.

\section{Acetylation of the basic C-terminal domains of CREB-2 by p300/CBP}

The sites of acetylation within the 351 amino acids of CREB-2 were mapped using a panel of CREB-2 GST- fusion fragments spanning the full-length protein. The GST-fusion fragments prebound to glutathione-Sepharose were incubated with CEM nuclear extract and radioactive acetyl-CoA as described above. Acetylation was detected in the C-terminal region of CREB-2 (Fig. 3), including not only the basic domain of the bZIP (from amino acid residue 270 to 300 ) but also the short basic domain (from 342 to 351) located downstream from the bZIP (Fig. 1). However, the GST-fusion protein containing only the CREB-2 C-terminal domain (from 263 to 351) was not acetylated after incubation with nuclear extract, suggesting that the cellular acetyltransferase that is involved in the CREB-2 acetylation is unable to interact with the C-terminal region of CREB-2.

Among the nuclear HATs identified and characterized 


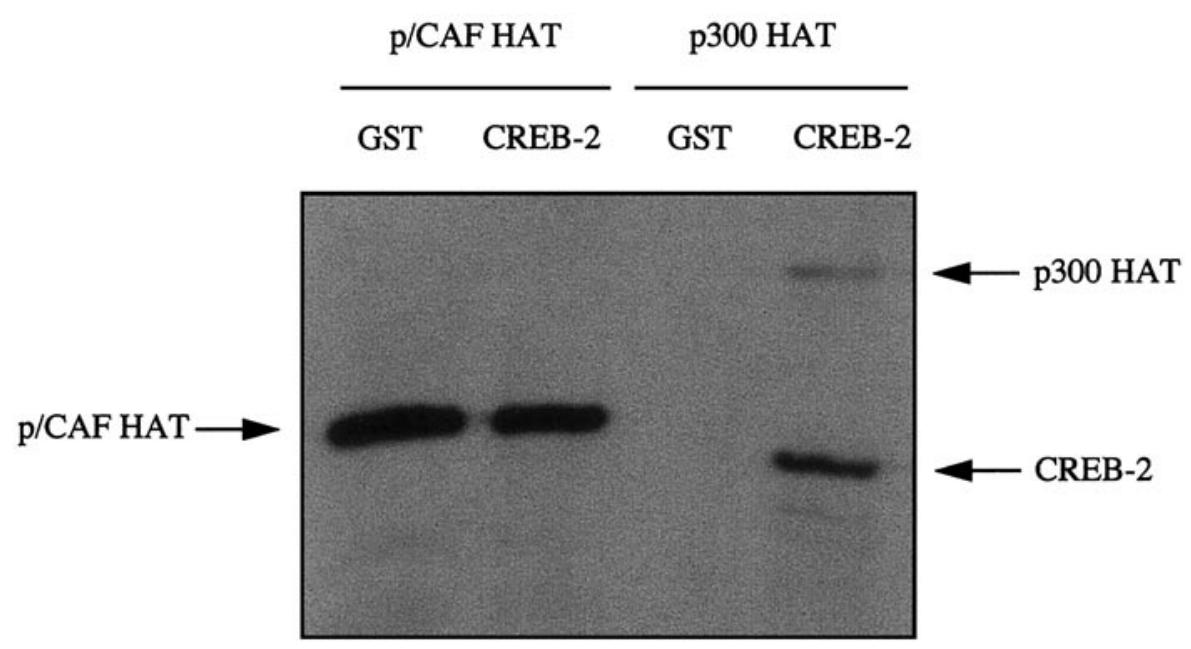

FIG. 4. CREB-2 is acetylated by p300 but not by p/CAF. Purified CREB-2 was incubated with ${ }^{3} \mathrm{H}$-acetyl-CoA and recombinant GST-p/CAF HAT or GST-p300 HAT. Reaction products were separated by SDS-PAGE and gels were autoradiographed. The products of autoacetylation, GST-p/CAF HAT, and GST-p300, used as positive controls, are indicated by arrows. The reactions were carried out with GST as negative controls.

to date, p300/CBP has been shown to interact with CREB-2 (Liang and Hai, 1997; Gachon et al., 2000). In addition, our previous studies using truncated proteins have shown that p300/CBP is unable to interact in vivo with the C-terminal region of CREB-2 (Gachon et al., 2000). Taken together, these results suggest that p300/ CBP could be involved in CREB-2 acetylation. To test this possibility, we performed in vitro acetylation assays using purified CREB-2 and GST-p300 HAT domain. Figure 4 shows that CREB-2 was acetylated by p300. On the other hand, when the same experiment was carried out with the HAT domain of p/CAF, CREB-2 was not acetylated (Fig. 4). These results strongly suggest that CREB-2 is acetylated by p300 but not by p/CAF.

\section{Activation of HTLV-I transcription in the presence of Tax is independent of the acetylation of CREB-2}

We wanted to determine whether acetylation of CREB-2 influences the HTLV-I transcription in the presence of Tax. We argued that identification of the lysines modified by p300 may give clues to the CREB-2 regulation by acetylation. Deletion analysis indicated that acetylation sites resided within the C-terminal region of CREB-2 (see Fig. 3) that contains several lysines. For this reason, we first mutated the lysine residues (to arginine) that were flanked by sequences well conformed to the consensus for the acetylation of nonhistone proteins (Gu and Roeder, 1997; Boyes et al., 1998). Three mutated lysines are within the short basic domain downstream from the bZIP (mutant M4) and the other mutated lysines (mutants M1, M2, M3, and M5) are in the basic domain of the bZIP (Fig. 5), some of which are implicated in the nuclear targeting of CREB-2 (KKLKK) (Cibelli et al., 1999) and probably in DNA binding.

The transcriptional activity of the mutants were tested by transient-transfection assays performed in CEM cells cotransfected with a luciferase reporter construct with a promoter containing three tandemly repeated copies of the cellular CRE site. Figure 5 shows that the transcriptional activity of the CREB-2 mutants M4 and M5 have significantly decreased, suggesting that acetylation of both basic domains are involved in the regulation of CREB-2 activity. Moreover, when the short basic C-terminal domain was completely deleted (mutant $M \Delta$ ), the transcriptional activity of CREB-2 decreased drastically (Fig. 5). Western blot analysis showed that the reduction of activity was not due to the lack of expression of the mutant CREB-2 proteins (data not shown). To determine whether the mutated lysines of M4 and M5 were effectively involved in acetylation of CREB-2, we performed in vitro acetylation assays using GST-p300 HAT domain. However, we were unable by this approach to discern significant changes in acetylation levels among the mutants (data not shown). For this reason, we mutated the other lysine residues present in the basic domain of the bZIP (mutants M6, M7, and M8). Although we detected a reduction of transcriptional activity for M8 (Fig. 5), again no significant reduction of acetylation was observed with this mutant (data not shown). This absence of difference in acetylation levels between the mutants confirm that multiple sites are acetylated, both in the basic domains (amino acid residues 270-300 and 342-351).

When the cotransfections were performed with Tax and a promoter containing three tandem copies of the HTLV-I promoter-proximal TxRE, M4, M5, and M8 were able to function as full activators of the HTLV-I transcription (Fig. 5). On the other hand, $\mathrm{M} \Delta$ remained unable to stimulate the viral transcription. This absence of transcription stimulation by the mutant $\mathrm{M} \Delta$ is obviously due to the incapacity of the mutant to interact with Tax. 


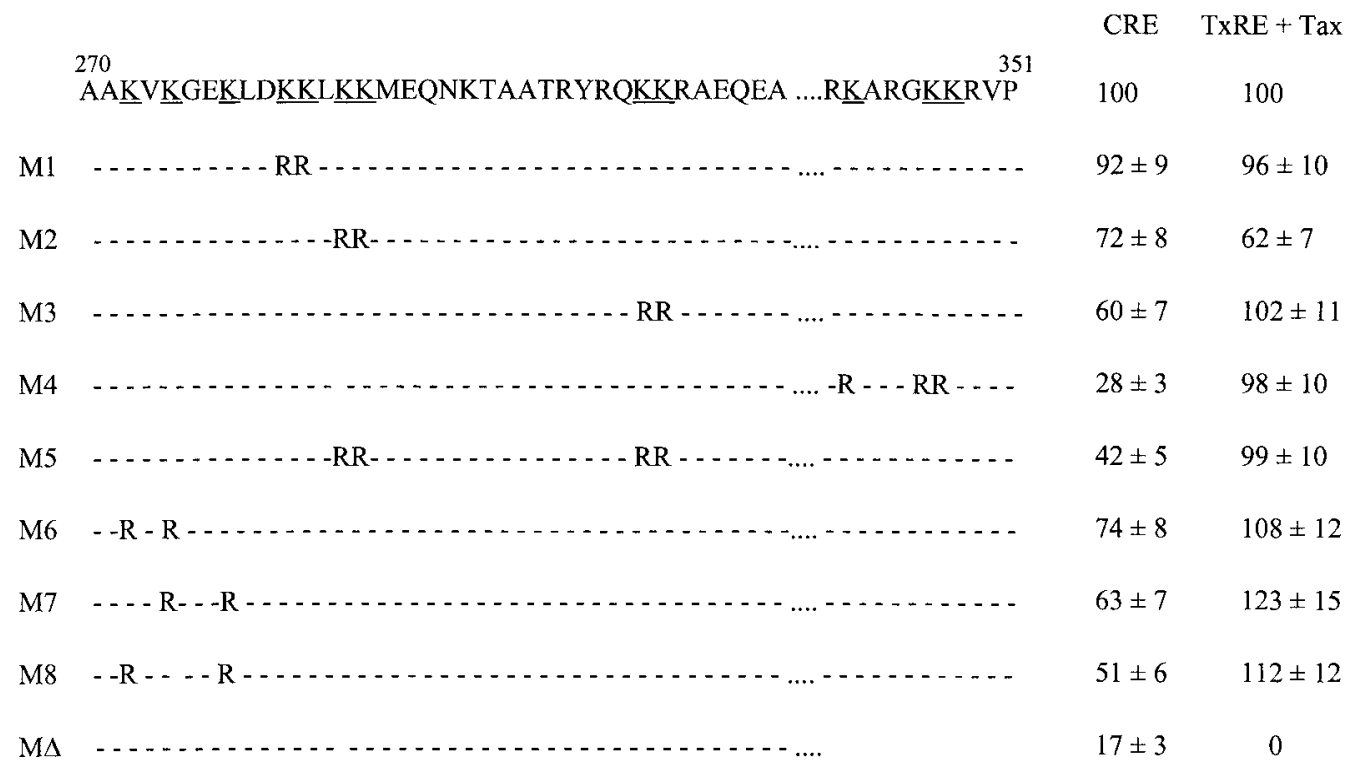

FIG. 5. Phenotypic analysis of the CREB-2 mutants. Functional properties of the CREB-2 mutants were analyzed by cotransfecting CEM cells with $2 \mu \mathrm{g}$ of luciferase gene driven by three tandem copies of the cellular palindromic CRE site or by three tandem copies of the viral promoter-proximal TxRE (in the presence of $1 \mu \mathrm{g}$ of pSG-Tax), $5 \mu \mathrm{g}$ of $\mathrm{pAC} \beta 1$ ( $\beta$-galactosidase containing reference plasmid), and $10 \mu \mathrm{g}$ of CREB-2 expression vector. The total amount of DNA in each series of transfection was equal, the balance being made up with the empty plasmids. The luciferase values were normalized for $\beta$-galactosidase activity and are presented as a percentage of the activity observed in cells transfected with the wild-type CREB-2. The values represent the mean $\pm \mathrm{SD}(n=3)$.

Indeed, we have previously demonstrated that the short basic C-terminal domain of CREB-2 is required for interaction with Tax and when this domain is completely deleted CREB-2 is no longer able to interact with Tax (Gachon et al., 2000). Taken together, our results show that the mutations of the lysine residues to arginine in the basic domains of CREB-2 affect its transcriptional activity. However, we find that the mutants remain capable of activating the viral transcription in the presence of Tax.

\section{DISCUSSION}

Several transcription factors that recruit p300/CBP and other coactivators possessing HAT activity have been shown to be acetylated. We and others have shown that CREB-2 interacts with p300/CBP (Liang and Hai, 1997; Gachon et al., 2000). Here, we demonstrate that CREB-2 is acetylated in vivo and p300 acetylates CREB-2 in vitro. We also show that CREB-2 is acetylated in two regions: the basic domain of the bZIP (from amino acid residue 270 to 300) and the short basic domain (from 342 to 351) located downstream from the bZIP. When the lysine residues present in these basic domains are mutated into arginine, the CREB-2 transcriptional activity decreases significantly. However, when we performed in vitro acetylation assays, we were unable to discern significant changes in acetylation levels of the mutants. Although this result is probably due to the existence of multiple acetylation sites present in the C-terminal region of CREB-2, we cannot totally exclude that the mutations could also affect CREB-2 structure and activity independent of acetylation.

On the other hand, in the presence of Tax, the HTLV-I transcription remains fully activated by these CREB-2 mutants, Tax counteracting the negative effect of the mutations. For the moment, we do not know why Tax is able to have such an effect. We have demonstrated that Tax interacted with CREB-2 bound to the three TxREs of the LTR promoter and stabilized the complex CREB-2/ TxRE (Gachon et al., 2000). Then, the LTR-associated Tax molecule is able to recruit p300/CBP (Kwok et al., 1996). Acetylation may also modulate a number of functional properties of a transcription factor such as CREB-2, including its sequence-specific DNA-binding activity, protein-protein interactions, and nucleocytoplasmic shuttling. Among the CREB-2 mutants that we have produced, some contain mutations in the region of CREB-2 involved in its nuclear targeting (Cibelli et al., 1999). However, it is obvious that acetylation of CREB-2 is not involved in its transport to the nucleus since all these mutants are still able to stimulate, in the presence of Tax, the viral transcription that occurs in the nucleus (Bex et al., 1998). Acetylation of CREB-2 could enhance its association with p300/CBP, as it has been recently described for c-Myb (Sano and Ishii, 2001). However, if this was the case, this effect would be indirect because we have found that the bZIP region of CREB-2 does not interact with p300/CBP in vivo (Gachon et al., 2000). At least, acetylation of CREB-2 could enhance the DNA affinity of CREB-2 for the CRE motif. This possibility could explain why the CREB-2 
mutants would be able to stimulate the viral transcription in the presence of Tax since Tax stabilizes the association between CREB-2 and TxRE by contacting nucleotides flanking the viral CRE-like motif (Kimzey and Dynan, 1998; Lenzmeier et al., 1998; Lundblad et al., 1998). This possibility should be investigated further to demonstrate the exact effect of acetylation on the transcriptional activity of CREB-2.

It is not the first time that Tax is described to be able to trans-activate the viral transcription independently of the modifications that are involved in the regulation of the activity of the transcription factors. Thus, CREB participates in Tax-mediated activation of the HTLV-I promoter without being phosphorylated by the protein kinase A (Laurance et al., 1997), whereas CREB normally interacts with $\mathrm{p300/CBP}$ in a phosphorylation-dependent manner (Chrivia et al., 1993; Kwok et al., 1994). All these observations confirm that the main function of the bZIP factors such as CREB and CREB-2, that bind to the viral promoter, is to provide a bridge between the viral promoter and Tax, Tax recruiting in turn p300/CBP to activate the viral transcription. Actually, we do not know whether p300/CBP is able to acetylate CREB-2 when CREB-2 is associated with Tax on the viral promoter. On the other hand, we did not detect any acetylation of Tax, suggesting that Tax is probably not acetylated by p300/ CBP. Taken together, these observations suggest that the main function of the p300/CBP recruitment to the HTLV-I promoter could be to induce local nucleosome modifications by histone acetylation and facilitate stable binding of components of the basal transcription machinery.

\section{MATERIALS AND METHODS}

\section{Plasmids, mutagenesis, and transfections}

The expression vectors pSG-Tax and pCI-CREB-2, and the luciferase reporter plasmid pminLUC-viral TxRE and pminLUC-cellular CRE, have been previously described (Gachon et al., 2000). Point mutations in the CREB-2 cDNA were performed by using the Altered Sites II Mammalian Mutagenesis System kit (Promega) according to the manufacturer's instructions and verified by DNA sequencing. The full-length CREB-2 and the mutated CREB-2 cDNAs were subcloned into the pGex bacterial expression vector and the glutathione $S$-transferase (GST)-tagged proteins were purified as described (Gachon et al., 1998). The pGex plasmids allowing the expression of the HAT domains of p300 and p/CAF were generous gifts from Eric Verdin and Tony Kouzarides, respectively.

The lymphoblastoid CEM cell line was obtained from the American Type Culture Collection (Bethesda, MD). Cells were cultured in RPMI 1640 medium supplemented with $1 \%$ penicillin streptomycin antibiotic mixture, $1 \%$ glutamax (Life Technologies, Eragny, France), and 10\% FCS (Life Technologies) to a density of $5 \times 10^{5}$ cells $/ \mathrm{ml}$ in a $5 \% \mathrm{CO}_{2}$ atmosphere. CEM cells were transiently cotransfected according to the previously published procedure (Thébault et al., 2000). Five micrograms of a $\beta$-galactosidase-containing plasmid $(p A C \beta 1)$ was included in each transfection for controlling of the transfection efficiency. The total amount of DNA in each series of transfection was equal, the balance being made up with empty pSG-5 or pCl-neo vector. Cell extracts equalized for protein content were used for luciferase and $\beta$-galactosidase assays (Thébault et al., 2000).

\section{GST pull-downs from nuclear extract}

GST-fusion proteins prebound to glutathione-Sepharose beads were incubated with $100 \mu \mathrm{g}$ CEM nuclear extract protein prepared as already described (Lemasson et al., 1998) in $500 \mu \mathrm{l}$ of $20 \mathrm{mM}$ HEPES pH 7.6, 100 $\mathrm{mM} \mathrm{KCl}, 1 \mathrm{mM}$ DTT, $0.1 \mathrm{mM}$ EDTA, 10\% glycerol, and 0.1\% NP-40 for $2 \mathrm{~h}$. Beads were washed five times in $500 \mu \mathrm{l}$ of the same buffer with $250 \mathrm{mM} \mathrm{KCl}$ and resuspended in 20 $\mu l$ of acetylation buffer.

\section{Acetyltransferase assays}

After incubation with nuclear extract, GST-fusion proteins were incubated at $30^{\circ} \mathrm{C}$ for $1 \mathrm{~h}$ with $0.25 \mu \mathrm{Ci}$ of ${ }^{3} \mathrm{H}$-acetyl-CoA (ICN) in acetylation buffer containing 50 mM HEPES pH 8.0, $1 \mathrm{mM}$ DTT, 10\% glycerol, $0.2 \mathrm{mM}$ phenylmethylsulfonyl fluoride, and $10 \mathrm{mM}$ sodium butyrate. Proteins were resolved by SDS-PAGE; the gels were fixed by Coomassie blue staining and subjected to signal amplification (Amplify; Amersham) prior to exposing to $X$-ray film. For the tests with p300 and p/CAF, CREB-2, subcloned into the $\mathrm{pQE}$ bacterial expression vector and purified as already described (Gachon et al., 2000), was incubated for $0.5 \mathrm{~h}$ in the presence of the HAT domain of p300 (amino acid residues 1195-1810) or $\mathrm{p} / \mathrm{CAF}$ (amino acid residues 352-658) in the same conditions than that presented above.

\section{in vivo $\left[{ }^{3} \mathrm{H}\right]$ sodium acetate labeling and immunoprecipitations}

Forty million exponentially CEM cells were centrifuged and resuspended in $5 \mathrm{ml}$ of medium containing $1 \mathrm{mCi}$ of $\left[{ }^{3} \mathrm{H}\right]$ sodium acetate per $\mathrm{ml}(10 \mathrm{Ci} / \mathrm{mmol} ; \mathrm{ICN})$ and $50 \mathrm{nM}$ Trichostatin (Sigma) and incubated for $1.5 \mathrm{~h}$. The cells were lysed in $50 \mathrm{mM}$ Tris $\mathrm{pH} 8.0,150 \mathrm{mM} \mathrm{NaCl}, 1 \mathrm{mM}$ DTT, 1 mM EDTA, 1\% Triton X-100, 0.2 mM phenylmethylsulfonyl fluoride, and $10 \mathrm{mM}$ sodium butyrate. Cell lysates were centrifuged at 10,000 $\mathrm{g}$ for $5 \mathrm{~min}$ and equal amounts of proteins (1 mg) were immunoprecipitated with polyclonal CREB-2 antibodies (Santa Cruz Biotechnology Inc., Santa Cruz, CA) or preimmune serum. The antibodies were captured by adding $15 \mu$ of a $50 \%$ slurry of protein A-Sepharose. After washing five times in the same buffer, immunoprecipitates were resolved by SDS- 
PAGE, fixed, and subjected to signal amplification and autoradiographed.

\section{ACKNOWLEDGMENTS}

This work was supported by institutional grants from the Centre National de la Recherche Scientifique (CNRS) and the Universite Montpellier I (UM I), and grants to J.M.M. from the Fondation de France and the Comité de l'Hérault de la Ligue contre le Cancer. F.G. is a fellow of the ARC. We thank Eric Verdin and Tony Kouzarides for the kind gift of the pGex plasmids, allowing the expression of the HAT domains of p300 and $\mathrm{p} / \mathrm{CAF}$, respectively.

\section{REFERENCES}

Bex, F., Yin, M. J., Burny, A., and Gaynor, R. B. (1998). Differential transcription activation by human T-cell leukemia virus type 1 Tax mutants is mediated by distinct interactions with CREB binding protein and p300. Mol. Cell. Biol. 18, 2392-2405.

Boyes, J., Byfield, P., Nakatani, Y., and Ogryzko, V. (1998). Regulation of activity of the transcription factor GATA-1 by acetylation. Nature 396, 594-598.

Cann, A. J., Rosenblatt, J. D., Wachsman, W., Shah, N. P., and Chen, I. S. (1985). Identification of the gene responsible for human T-cell leukemia virus transcriptional regulation. Nature 318, 571-574.

Caron, C., Mengus, G., Dubrowskaya, V., Roisin, A., Davidson, I., and Jalinot, P. (1997). Human $\mathrm{TAF}_{\|} 28$ interacts with the human $T$ cell leukemia virus type I Tax transactivator and promotes its transcriptional activity. Proc. Natl. Acad. Sci. USA 94, 3662-3667.

Caron, C., Rousset, R., Béraud, C., Moncollin, V., Egly, J.-M., and Jalinot, P. (1993). Functional and biochemical interaction of the HTLV-I Tax1 transactivator with TBP. EMBO J. 12, 4269-4278.

Chrivia, J. C., Kwok, R. P. S., Lamb, N., Hagiwara, M., Montminy, M. R., and Goodman, R. H. (1993). Phosphorylated CREB binds specifically to the nuclear protein CBP. Nature 376, 855-859.

Cibelli, G., Schoch, S., and Thiel, G. (1999). Nuclear targeting of CAMP response element binding protein 2 (CREB2). Eur. J. Cell Biol. 78, 642-649.

Clemens, K. E., Piras, G., Radonovich, M. F., Choi, K. S., Duvall, J. F., DeJong, J., Roeder, R., and Brady, J. N. (1996). Interaction of the human T-cell lymphotropic virus type 1 Tax transactivator with transcription factor IIA. Mol. Cell. Biol. 16, 4656-4664.

Felber, B. K., Paskalis, H., Kleinman-Ewing, C., Wong-Staal, F., and Pavlakis, G. N. (1985). The pX protein of HTLV-I is a transcriptional activator of its long terminal repeats. Science 229, 675-679.

Franklin, A. A., Kubik, M. F., Uittenbogaard, M. N., Brauweiler, A., Utaisincharoen, P., Matthews, M. A., Dynan, W. S., Hoeffler, J. P., and Nyborg, J. K. (1993). Transactivation by the human T-cell leukemia virus Tax protein is mediated through enhanced binding of activating transcription factor-2 (ATF-2) ATF-2 response and CAMP elementbinding protein (CREB). J. Biol. Chem. 268, 21225-21231.

Fujisawa, J. I., Seiki, M., Kiyokawa, T., and Yoshida, M. (1985). Functional activation of the long terminal repeat of human T-cell leukemia virus type I by a trans-acting factor. Proc. Natl. Acad. Sci. USA 82, 22772281.

Fujisawa, J. I., Seiki, M., Sato, M., and Yoshida, M. (1986). A transcriptional enhancer sequence of HTLV-I is responsible for trans-activation mediated by p40x of HTLV-I. EMBO J. 5, 713-718.

Gachon, F., Gaudray, G., Thebault, S., Basbous, J., Koffi, A. J., Devaux, C., and Mesnard, J. M. (2001). The CAMP response element binding protein-2 (CREB-2) can interact with the C/EBP-homologous protein (CHOP). FEBS Lett. 502, 57-62.

Gachon, F., Péléraux, A., Thébault, S., Dick, J., Lemasson, I., Devaux, C., and Mesnard, J. M. (1998). CREB-2, a cellular CRE-dependent transcription repressor, functions in association with Tax as an activator of the human T-cell leukemia virus type 1 promoter. J. Virol. 72, 8332-8337.

Gachon, F., Thebault, S., Peleraux, A., Devaux, C., and Mesnard, J. M. (2000). Molecular interactions involved in the transactivation of the human T-cell leukemia virus type 1 promoter mediated by Tax and CREB-2 (ATF-4). Mol. Cell. Biol. 20, 3470-3481.

Gu, W., and Roeder, R. G. (1997). Activation of p53 sequence-specific DNA binding by acetylation of the p53 C-terminal domain. Cel/ 90, 595-606.

Hai, T., and Curran, T. (1991). Cross-family dimerization of transcription factors Fos/Jun and ATF/CREB alters DNA binding specificity. Proc. Natl. Acad. Sci. USA 88, 3720-3724.

Hai, T., and Hartman, M. G. (2001). The molecular biology and nomenclature of the activating transcription factor/cAMP responsive element binding family of transcription factors: Activating transcription factor proteins and homeostasis. Gene 273, 1-11.

Hai, T., Liu, F., Coukos, W. J., and Green, M. R. (1989). Transcription factor ATF cDNA clones: An extensive family of leucine zipper proteins able to selectively form DNA-binding heterodimers. Genes Dev. 3, 2083-2090.

Jiang, H., Lu, H., Schiltz, R. L., Pise-Masison, C. A., Ogryzko, V. V., Nakatani, Y., and Brady, J., N. (1999). PCAF interacts with Tax and stimulates Tax transactivation in a histone acetyltransferase-independent manner. Mol. Cell. Biol. 19, 8136-8145.

Karpinski, B. A., Morle, G. D., Huggenvik, J., Uhler, M. D., and Leiden, J. M. (1992). Molecular cloning of human CREB-2: An ATF/CREB transcription factor that can negatively regulate transcription from the CAMP response element. Proc. Natl. Acad. Sci. USA 89, 48204824.

Kimzey, A. L., and Dynan, W. S. (1998). Specific regions of contact between human T-cell leukemia virus type I Tax protein and DNA identified by photocross-linking. J. Biol. Chem. 273, 13768-13775.

Kwok, R. P. S., Laurance, M. E., Lundblad, J. R., Goldman, P. S., Shih, H.-M., Connor, L. M., Marriott, S. J., and Goodman, R. H. (1996). Control of CAMP-regulated enhancers by the viral transactivator Tax through CREB and the coactivator CBP. Nature 370, 223-226.

Kwok, R. P. S., Lundblad, J. R., Chrivia, J. C., Richards, J. P., Bächinger, H. P., Brennan, R. G., Roberts, S. G. E., Green, M. R., and Goodman, R. H. (1994). Nuclear protein CBP is a coactivator for the transcription factor CREB. Nature 370, 223-226.

Laurance, M. E., Kwok, R. P. S., Huang, M. S., Richards, J. P., Lundblad, J. R., and Goodman, R. H. (1997). Differential activation of viral and cellular promoters by human T-cell lymphotropic virus-1 Tax and cAMP-responsive element modulator isoforms. J. Biol. Chem. 272, 2646-2651.

Lemasson, I., Thébault, S., Sardet, C., Devaux, C., and Mesnard, J. M. (1998). Activation of E2F-mediated transcription by human T-cell leukemia virus type I Tax protein in a p16 ${ }^{\text {INK4A }}$-negative T-cell line. J. Biol. Chem. 273, 23598-23604.

Lenzmeier, B. A., Giebler, H. A., and Nyborg, J. K. (1998). Human T-cell leukemia virus type 1 Tax requires direct access to DNA for recruitment of CREB binding protein to the viral promoter. Mol. Cell. Biol. 18, 721-731.

Liang, G., and Hai, T. (1997). Characterization of human activating transcription factor 4 , a transcriptional activator that interacts with multiple domains of cAMP-responsive element-binding protein (CREB)-binding protein (CBP). J. Biol. Chem. 272, 24088-24095.

Lundblad, J. R., Kwok, R. P. S., Laurance, M. E., Huang, M. S., Richards, J. P., Brennan, R. G., and Goodman, R. H. (1998). The human T-cell leukemia virus-1 transcriptional activator Tax enhances CAMP-responsive element-binding protein (CREB) binding activity through interactions with the DNA minor groove. J. Biol. Chem. 273, 1925119259.

Mesnard, J. M., and Devaux, C. (1999). Multiple control levels of cell proliferation by human T-cell leukemia virus type 1 Tax protein. Virology 257, 277-284.

Reddy, T. R., Tang, H., Li, X., and Wong-Staal, F. (1997). Functional 
interaction of the HTLV-1 transactivator Tax with activating transcription factor-4 (ATF4). Oncogene 14, 2785-2792.

Sano, Y., and Ishii, S. (2001). Increased affinity of c-Myb for CREBbinding protein (CBP) after CBP-induced acetylation. J. Biol. Chem. 276, 3674-3682.

Shimotohno, K., Takano, M., Teruuchi, T., and Miwa, M. (1986). Requirement of multiple copies of a 21 nucleotide sequence in the $U 3$ region of human T-cell leukemia virus type I and type II long terminal repeats for trans-acting activation of transcription. Proc. Natl. Acad. Sci. USA 83, 8112-8116.

Sodroski, J. G., Patarca, R., Rosen, C. A., Wong-Staal, F., and Haseltine, $W$. A. (1985). Location of the trans-activating region on the genome of human T-Iymphotrophic virus type III. Science 229, 74-75.

Suzuki, T., Fujisawa, J. I., Toita, M., and Yoshida, M. (1993). The transactivator Tax of human T-cell leukemia virus type I (HTLV-I) interacts with cAMP-responsive element (CRE) binding and CRE modulator proteins that bind to the 21-base-pair enhancer of HTLV-I. Proc. Natl. Acad. Sci. USA 90, 610-614.

Thébault, S., Gachon, F., Lemasson, I., Devaux, C., and Mesnard, J. M. (2000). Molecular cloning of a novel human I-mfa domain-containing protein that differently regulates HTLV-I and HIV-1 expression. J. Biol. Chem. 275, 4848-4857.

Tsujimoto, A., Nyunoya, H., Morita, T., Sato, T., and Shimotohno, K.
(1991). Isolation of cDNAs for DNA-binding proteins which specifically bind to a tax-responsive enhancer element in the long terminal repeat of human T-cell leukemia virus type I. J. Virol. 65, 1420-1426.

Vinson, C. R., Hai, T., and Boyd, M. (1993). Dimerization specificity of the leucine zipper-containing bZIP motif on DNA binding: Prediction and rational design. Genes Dev. 7, 1047-1058.

Wagner, S., and Green, M. R. (1993). HTLV-I Tax protein stimulation of DNA binding of bZIP proteins by enhancing dimerization. Science 262, 395-399.

Waltzer, L., and Bienz, M. (1998). Drosophila CBP represses the transcription factor TCF to antagonize Wingless signalling. Nature 395, 521-525.

Yin, J. Y., and Gaynor, R. B. (1996). Complex formation between CREB and Tax enhances the binding affinity of CREB for the human T-cell leukemia virus type 121 -base-pair repeats. Mol. Cell. Biol. 16, 31563168.

Yoshida, M. (2001). Multiple viral strategies of HTLV-1 for dysregulation of cell growth control. Annu. Rev. Immunol. 19, 475-496.

Zhao, L. J., and Giam, C.-Z. (1992). Human T-cell lymphotropic virus type I (HTLV-I) transcriptional activator, Tax, enhances CREB binding to HTLV-I 21-base-pair repeats by protein-protein interaction. Proc. Natl. Acad. Sci. USA 89, 7070-7074. 